\title{
التميز فى ضوء نموذج رينزوالي
}

إعداد

الباحثة / أمنية انس عحم الطاهر عواد'

\section{إشر افـ}

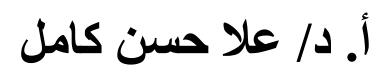

أستاذ مناهج وطرق تدريس الطفل

كلية التربية للطفولة المبكرة - جامعة القاهرة
أ.د / كمال الدين حسين

أستاذ الأدب المسرحي و الحكايات الثعبية

كلية التربية للطفولة المبكرة - جامعة القاهرة

مقدمة

لما كان للتميز و التقام أهمية باللغة فى نمو المجتمعات وتحضرها و العمل على رفعتها، لما كان الاهتمام

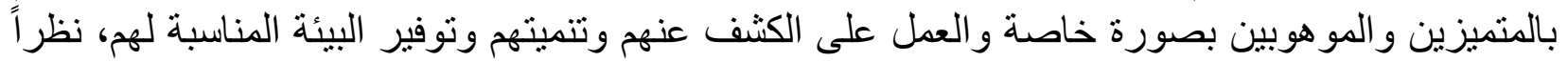

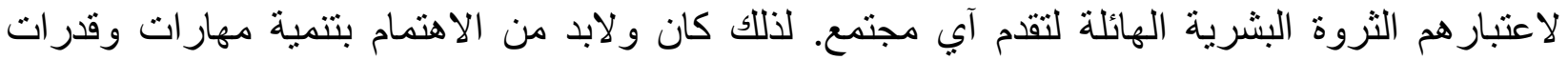

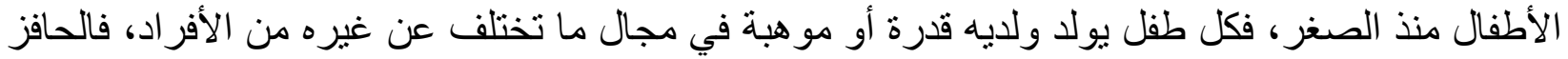

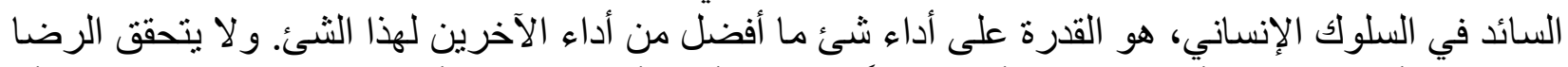

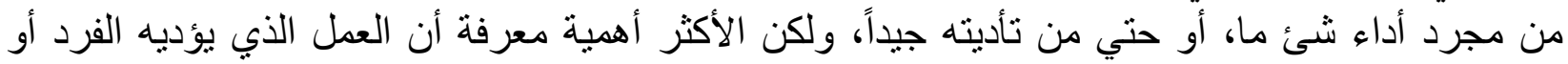

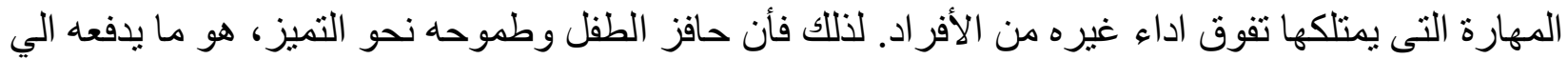

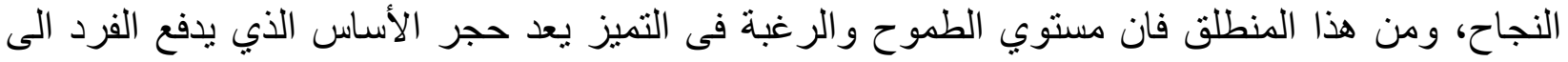
النجاح و التميز و استغلال ما لايه من مهار ات وقات وقدرات.

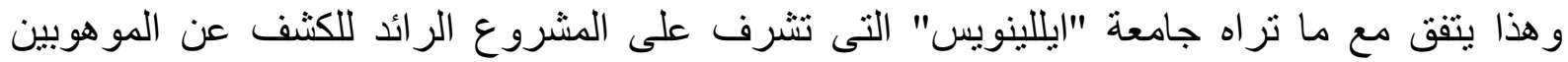

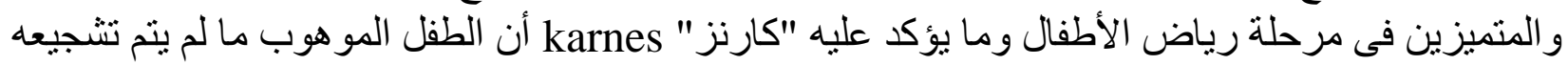

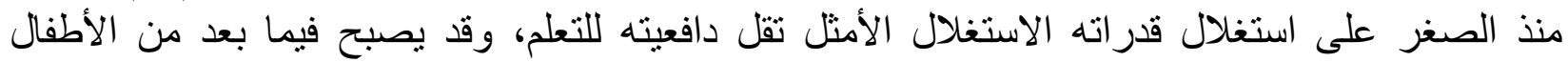

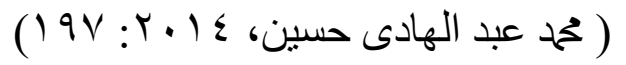
منخفضي التحصيل الاكاديمى. ويقدم رينزولى في ذللك مفهوم الحلقات الثناث للتميز باعتبار الأطفال المتميزون هم أولئلك القادرون

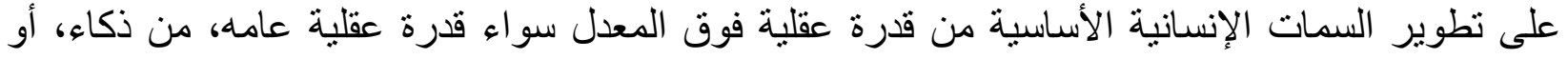

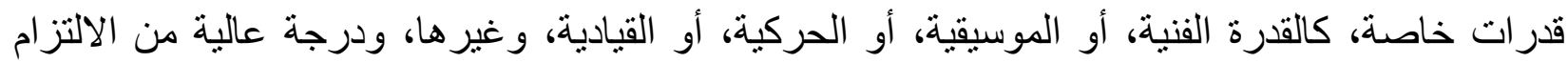

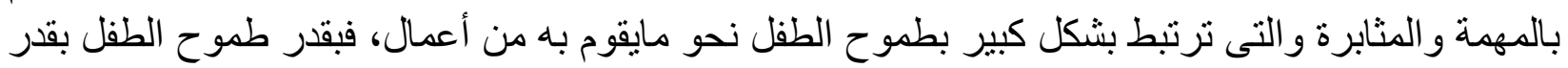




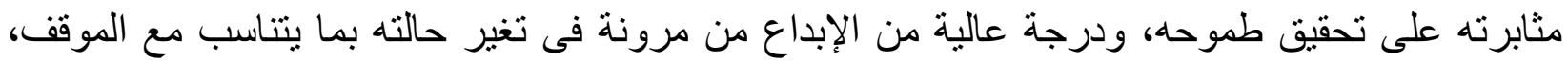

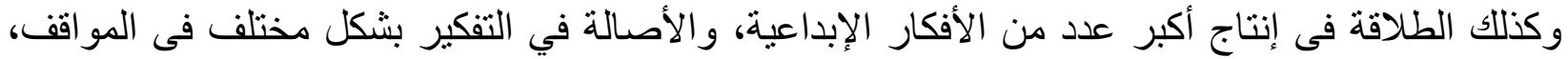

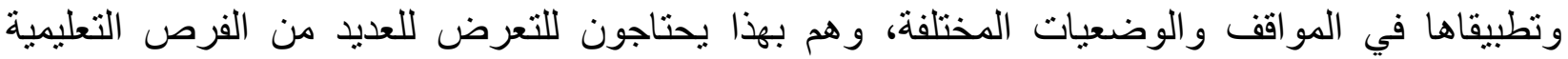

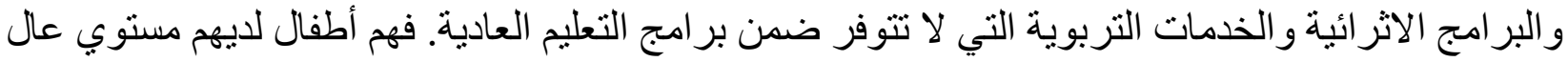
من الطموح نحو قدر اتهم.

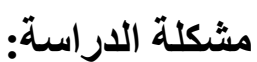

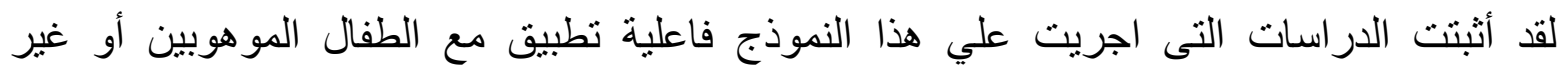

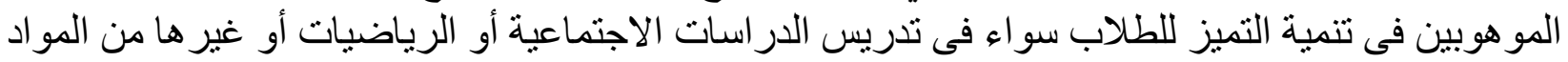
فى المرحلة الاعدادية ولكن لم يطبق هذا النموذج مع أطفال ما قبل التبل المدرسة.

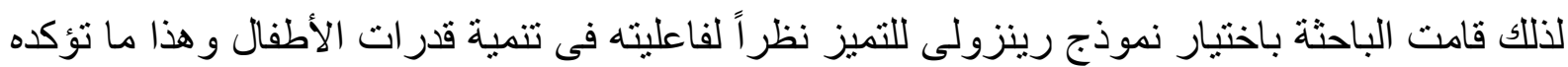

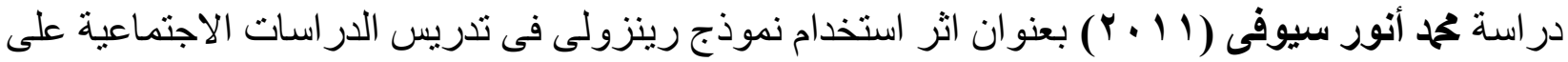

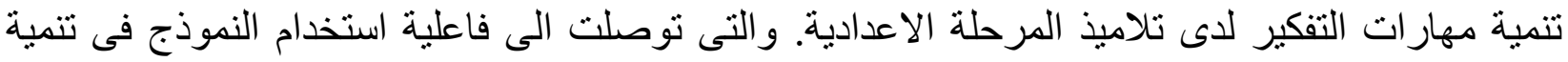
مهار ات التفكير

ووفقاً لتقسيم رينزوالى لهجالات التميز الى ثلاث مجالات وهم المجال العلمى والمجال الفنى والمجال

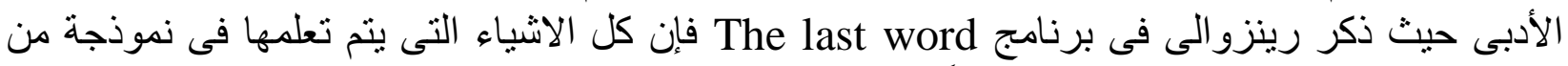

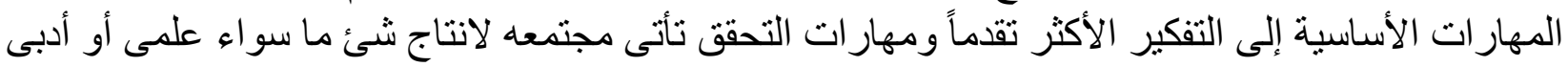

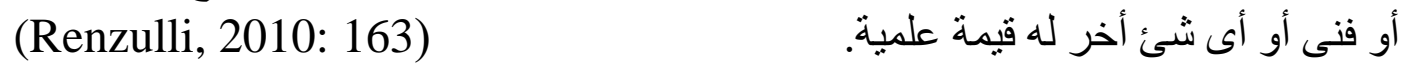
تساؤلات البحث: يحاول البحث الإجابة على التساؤلات الاتيه:

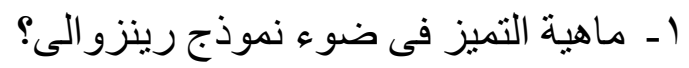

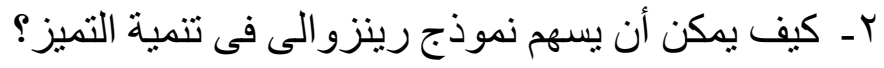

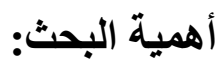
تتضح أهمية البحث الحالي من خلال: ا ـ تحديد مفهوم التميز فى ضوء نموذج رينزو الى.

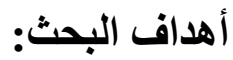
1 ـ إلقاء الضوء على التميز وتتميته عند الأطفال.

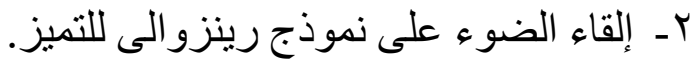

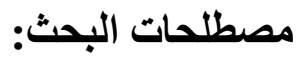

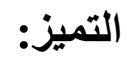

عرفت مكتبة التربية الاميركي أن الأطفال المتميزين هم الذين يتم الكثف عنهم من قبل مهنيين ومتخصصين ـ و الذين تكون لديهم قدر ات و اضحة ومقدر الات على الإنجاز المرتفع. 


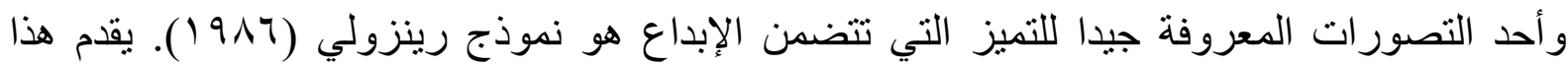

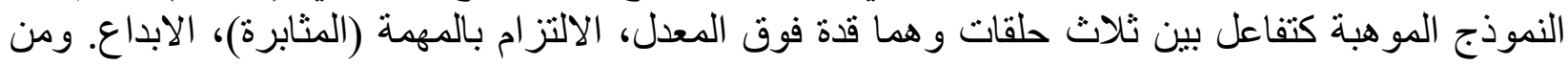

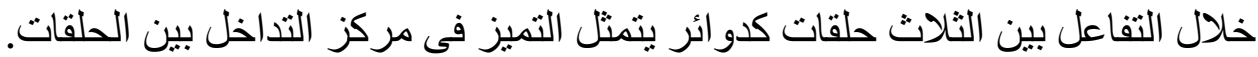

(miller. 2012: 94-95)

التعريف الإجرائى للتميز: هو تفاعل ثلاث حلقات حلقات متدخلة وهما قدرة عقلية فوق المعدل ، المثابرة، والإبداع.

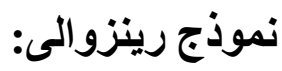

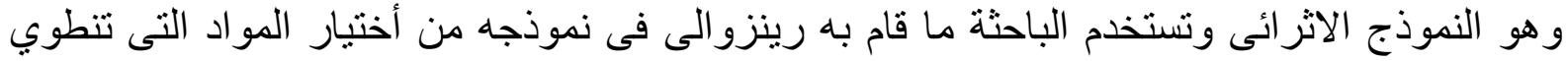

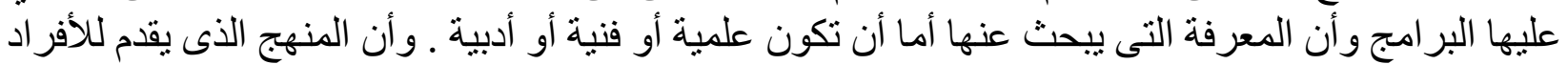
يجب أن يتوفر به الخبر ات الإثرائية الاتية: المتعه و التحدى وفى مجال التئمام الأفر اد.

فيذكر رينزو الى أن المعرفة ليس لها قيمة و الابداع أيضاً ليس له قيمة الا إذا كنا نستطيع تطبيقة على شئ ما.

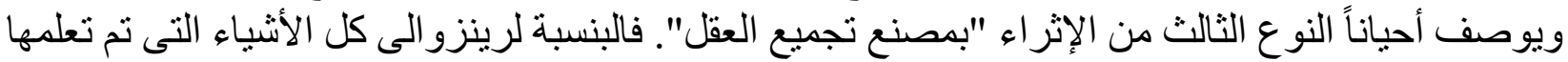

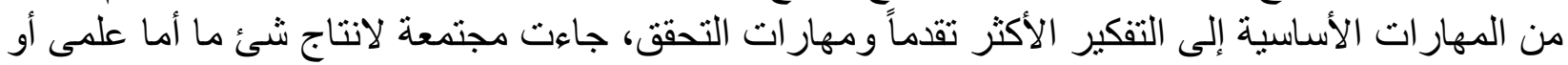
(the last word. 2010: 163)

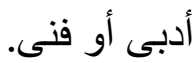

\section{منهج الاراسة:}

يتبع البحث الحالى المنهج الوصفى التحليلي للتعرف على نموذج رينزو الى للتميز الاطار النظرى والاراسات السابقة:

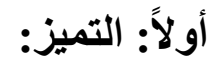

الإنسان المتميز هو القادر على الإنجاز بشكل متفرد لذلك نجده بظهر بصمته الفريدة على أدائه

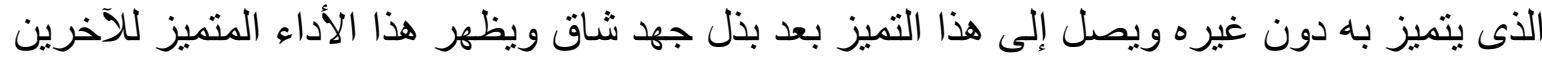

$$
\begin{aligned}
& \text { (كاريمان بدير: · ( • T، •0) } \\
& \text { ويمكن تقديره وقياسه . }
\end{aligned}
$$

ويعد تعريف ويتي( Witty, 1958 للتميز من التعريفات الاكثر ليير اليه فيري أن هناك أطفال

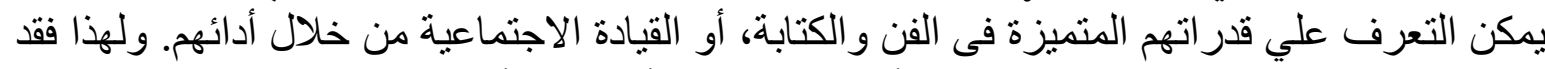

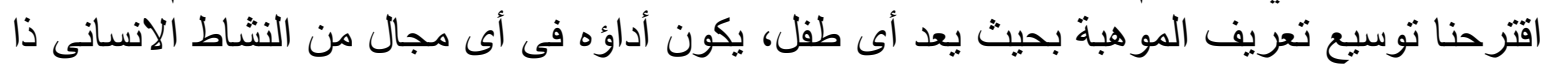

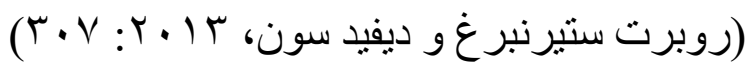

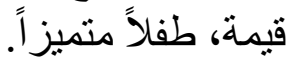

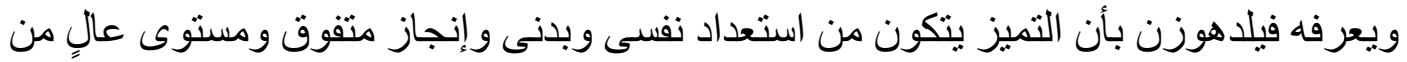

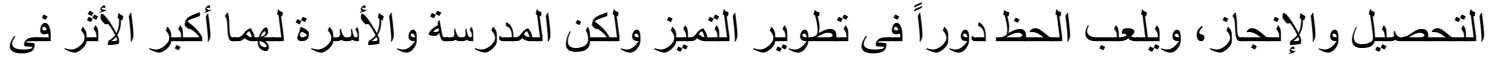
تلبية حاجات المتميزين. وكذللك يرى أن مفهوم التميز يحتوى على التيز

$$
\begin{aligned}
& \text { القدرة العقلية العامة. } \\
& \text { ه } \\
& \text { مفهوم الذات الايجابى. }
\end{aligned}
$$




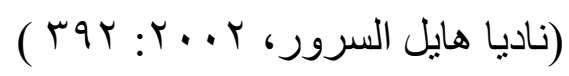

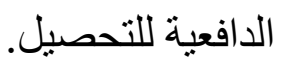

وبهذا التعريف نجد أن فلدهوزن يصنف المو هبة على أنها من محتويات ومكونات التميز فهى بذلك ضروريه للتميز و أساس فيه و هي خطوة مبدأيه للتميز.

الفرق بين الموهبة والتفوق والتميز:

يرى كثير العلماء أمثال رينزولى Renzuli أن الموهبة و التفوق و التميز كلاهما وجهان لعمله

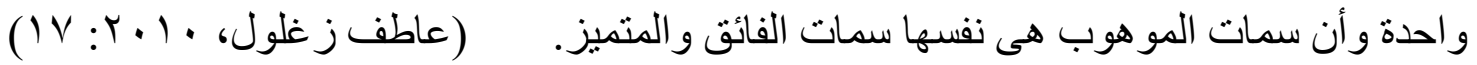

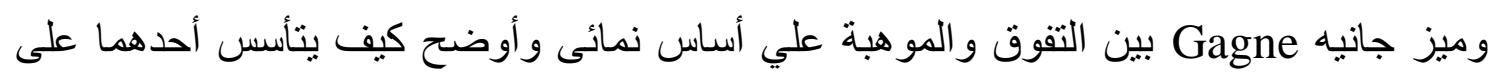

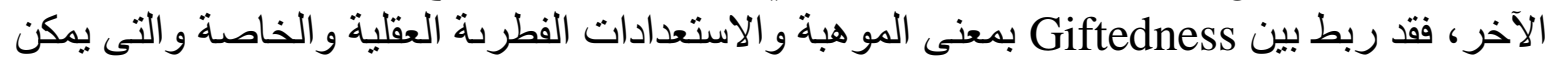

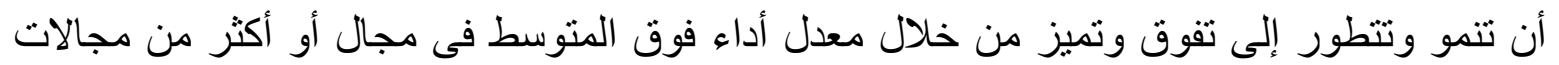

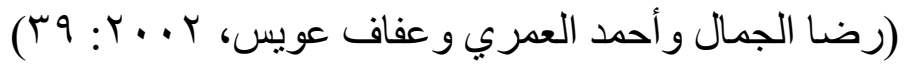
النشاط الأنسانى. و أنثار جانية إلى العو امل و المحفز ات التى من شأنها تحول الاستعدادات الفطرية (الموهبة) إلى أداء منميز (تفوق) تنقسم إلي: 1 - مـ التعليم و التندريب و الممارسة. r ـ المحفز ات الثخصية: وهى العو امل التى تتعلق بشخصية المو هوب نفسه، وتتقسم الى شقين:

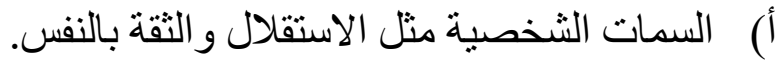
ب) الدافعية وتثمل المبادرة- المثابرة- المبادأة والميول.

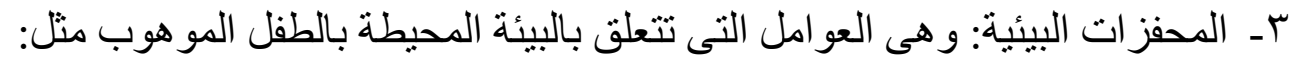

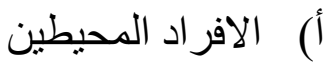

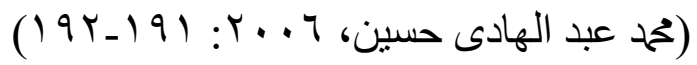

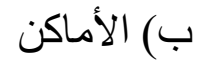

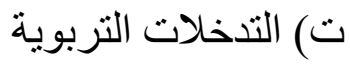

وبهذا السياق يقول (كوكس): "بإمكاننا أن نتحدث عن موسيقين وكتاب، و وعلماء (موهو بين) ولكن ولن

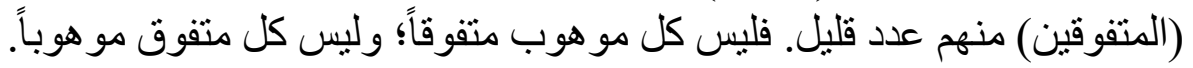

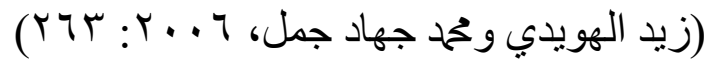
بينما فرق جانيت Janet بين مفهوم الموهبة و التفوق كما يأتى : لئي - - المو هبة قدرة بينما التفوق أداء. - العامل الرئيسى فى الموهبة ور انى بينما العامل الرئيسى فى التفوق بيئى.

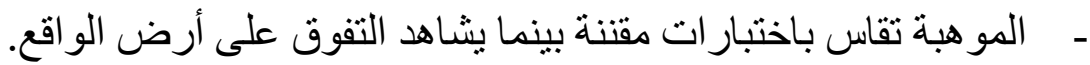

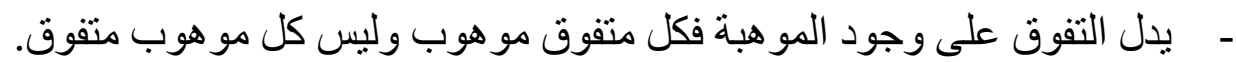

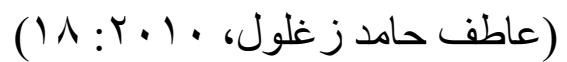
- المو هبة طاقة كامنة و التفوق نتاج لتلك الطاقة.

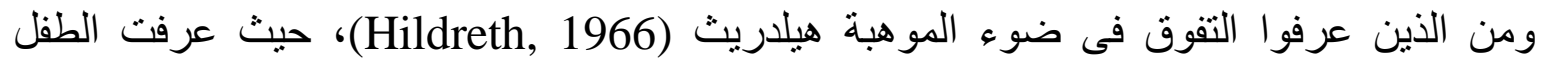
المتفوق بأنه " الطفل الموهوب، سواء أكانت مو هبته في مجال أكاديمى أو كانت فى مجال آخر مثل 
الموسيقى و الرسم و التمثيل، وتؤكد هيلدريث أن هنالك مواهب تظهر وتتفتح عند بعض الأفر اد نتيجة التربية

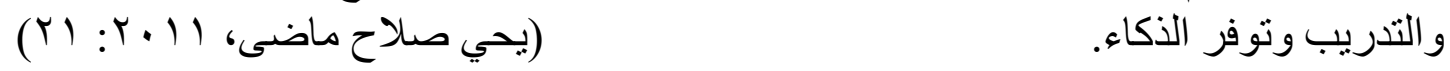

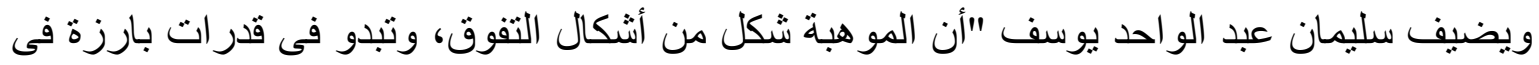

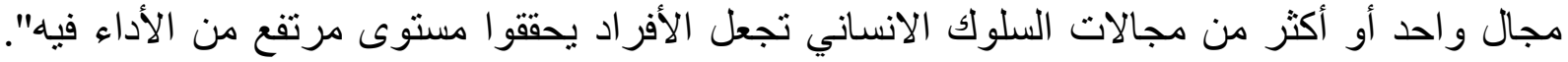

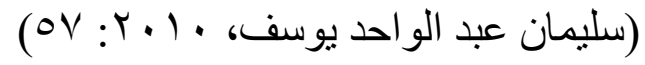

ونلخص مما سبق وفقاً لاتفاق كلاً من (فلدهوزن و سليمان عبد الواحد وجانية) أن الموهبة و التميز

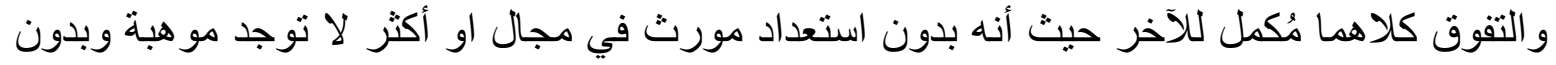

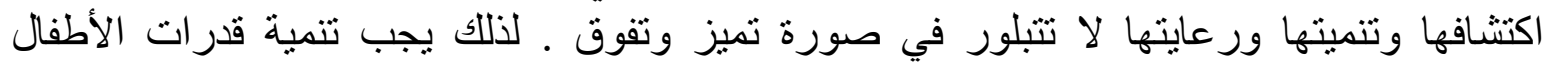
بإعطائهم الفرصة للتعبير عن مواهبهم وقدر اتهم و إكسابهم المهار وتهات الأساسية التى تعمل علي تميز هم

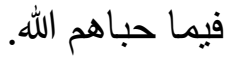

ووفقاً لأحدث الدراسات تبين أن نسبة المبدعين و المو هوبين من الأطفال من سن الو لادة إلى السنة

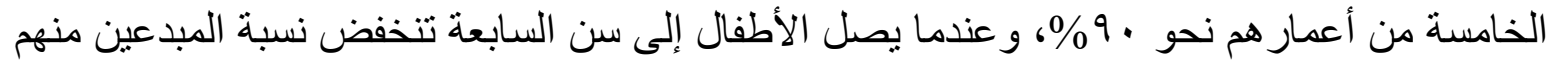

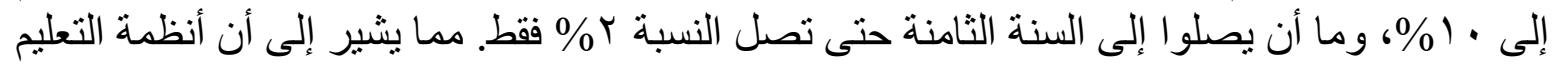

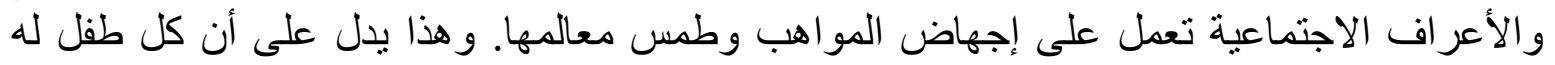

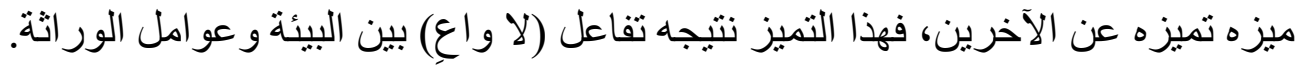

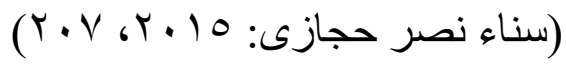

و هذا دليل واضح على أهميه مرحلة رياض الأطفال فى تثكيل جيل كبير من المتميزين و التى إذا

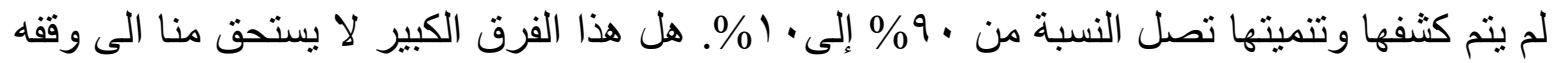

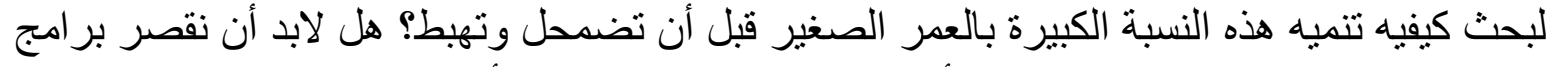

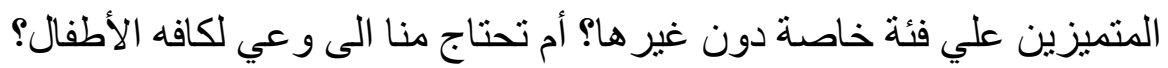

ثانياً: نموذج رينزوالى للتميز: يذكر نموذج رينزو الي ثلاث مهار ات مندخلة للتميز و التي تعرف بمفهوم الحلقات الثناث للتميز والتى عن طريقها يتميز الفرد فى مجال ما وهما:

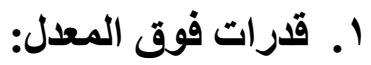

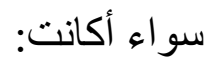

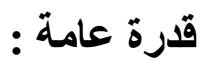

وتتضمن مستويات عالية من التفكير المجرد، قدرات عددية، علاقات مكانبة، الطموح الفكرى المنوقد

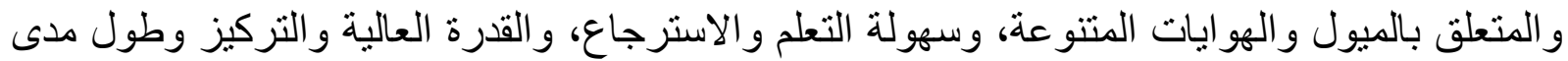
الانتباه، دقة الملاحظة و الحذر الثديد والإنجاز فوق المتوسط. (نايفة قطامى، 10 ــץ: (ع) 


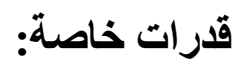

وهى تطبيق إى عنصر من عناصر القدرة العقلية العامة فى واحد أو أكثر من مجالات المعرفة فئلة

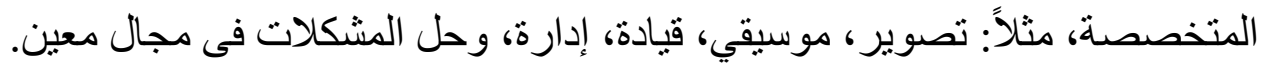

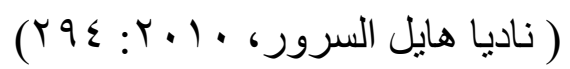

ويذكر رينزو الى انه لا يمكن قياس العديد من القدرات الخاصة بسهولة عن طريق الاختبار ات ، بل

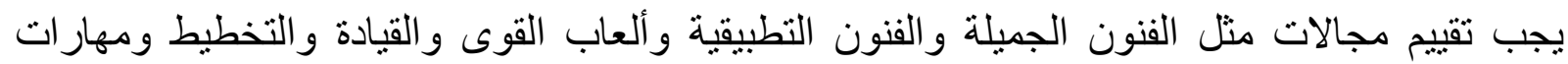

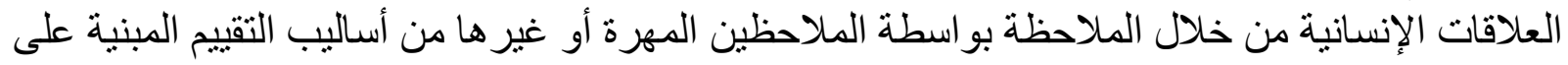
( Renzulli ,2016: 70 )

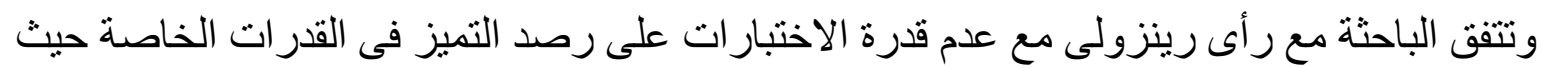

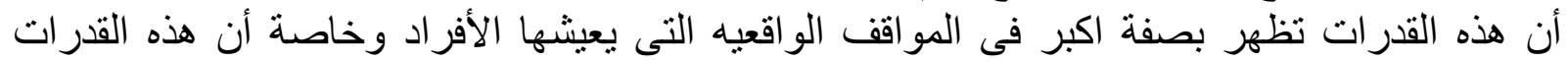
تختلف بأختلاف الموقف الموجود به المتميز.

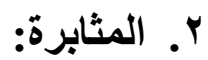

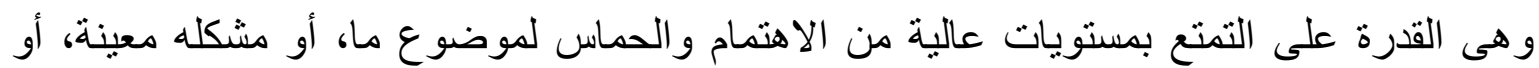

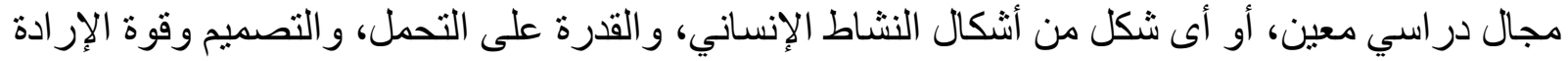

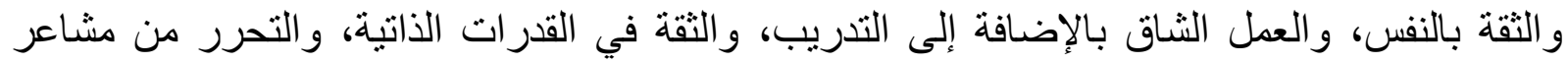

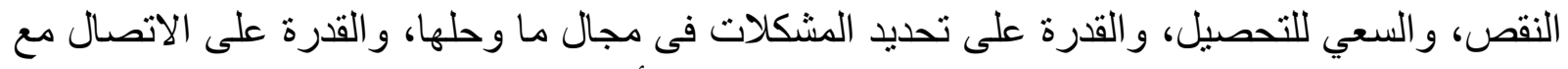

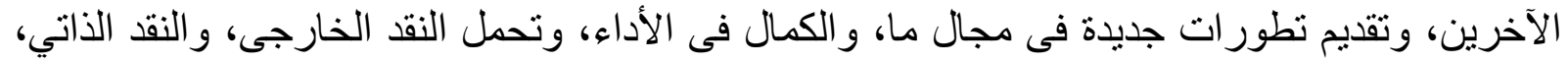
وتطوير الحس الجمالى، و التفوق في العمل، وتقدير أعمال الآخرين.

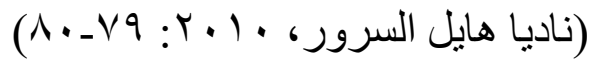

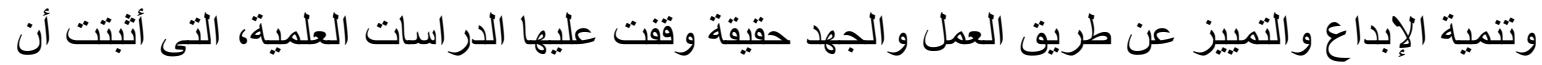

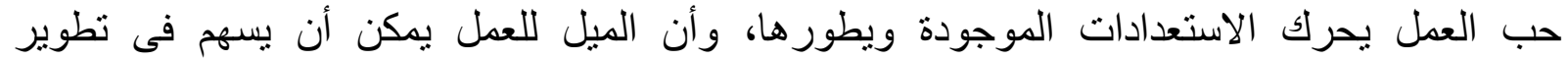

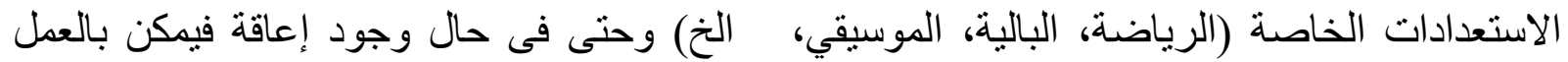

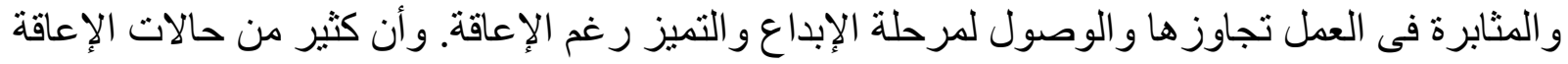

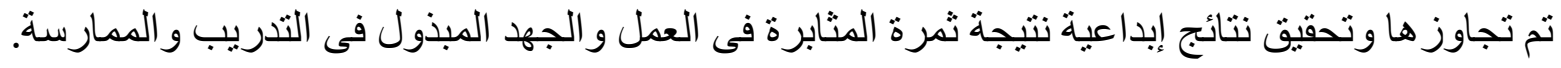

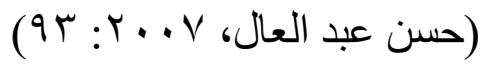

فبذللك نرى أن المثابرة على العمل من المهار ات الأساسية التى تساعد على الابداع و التميز و انها وسيلة

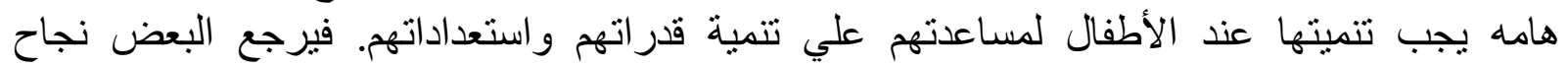
منتسورى فى جذب انتباه الأطفال إليها وتنمية قدرات الإبداع لديهر إلى الطرق الإنى الإبداعية التى استخدمنها 
فى تللك المدارس، و التى اعتمدت على التعليم من خلال العمل و إعطاء الأطفال الحرية الكاملة فى اكتشاف ما حولهم بالممارسة العملية ولقد كانت هذه المدارس تدعم الإبداع وتتمية من خلال مهار الات عملية جذابة.

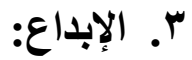

هو القدرة على التعامل بطريقة سهلة، ومريحة مع المشكلات الغامضة، أو غير المحددة، وإئاد وإيجاد

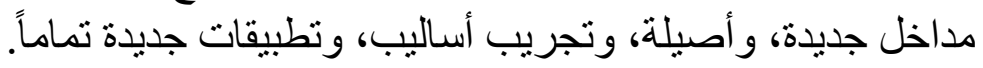

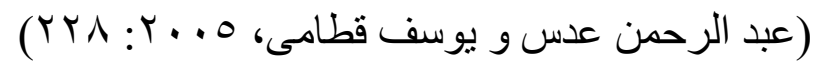

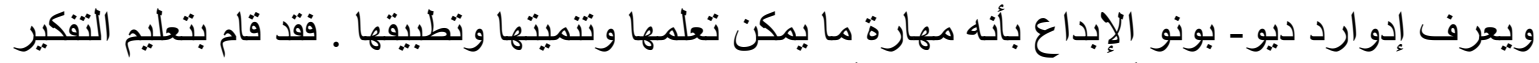

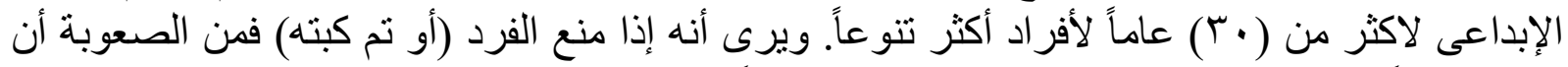

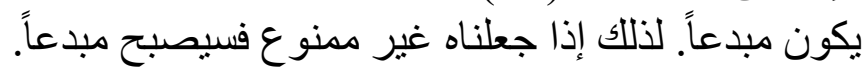

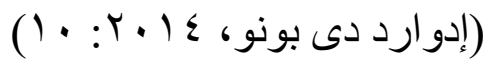

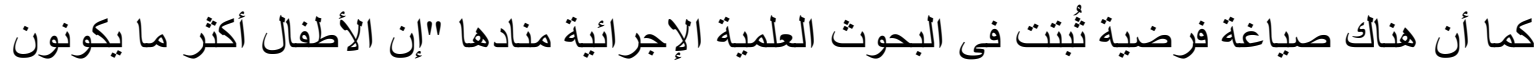

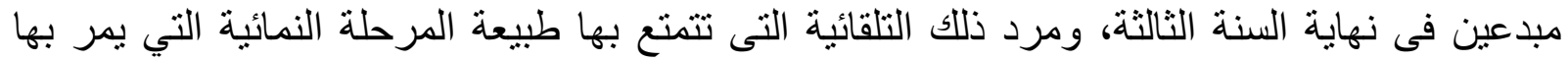

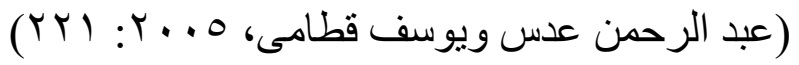

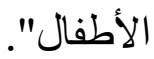

\section{التوصيات:}

$$
\text { فى ضوء ما سبق توصي الباحثة بالتالى: }
$$

- التعرف بشكل و اسع على العالم رينزو اللى وما جاء به فيى سبيل تحقيق التميز.

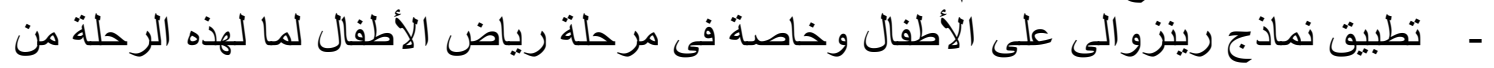
أهمية بالغه. - توعية القائمين على رعاية الأطفال بنماذج التفوق والتميز سواء للفئات الخاصة أو الأطفال العادين. 


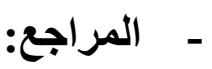

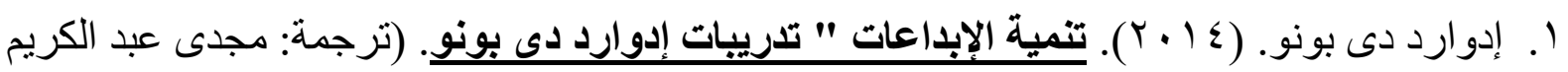

$$
\text { حبيب). القاهرة: دار الفكر العربي. }
$$

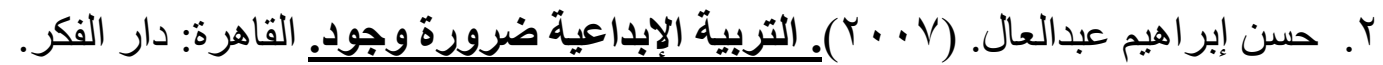

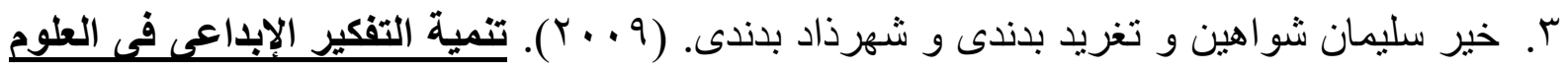
ووالرياضيات. عمان: دار المسيرة للنشر و التوزيع و الطباعة. لهئ.

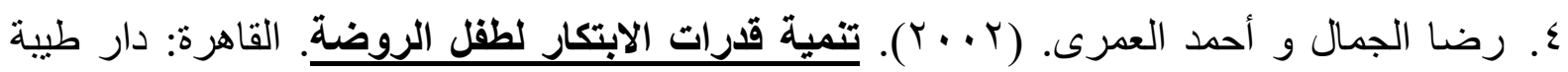

$$
\text { للطباعة. }
$$

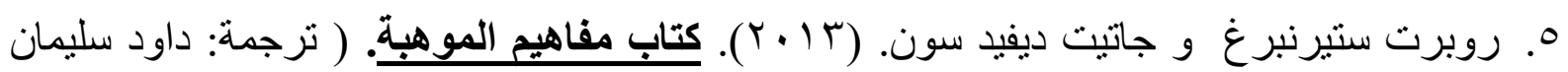

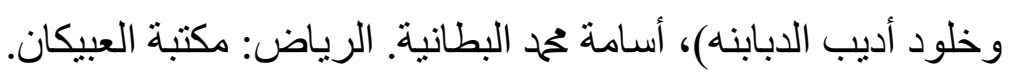

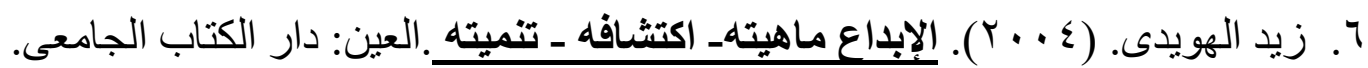

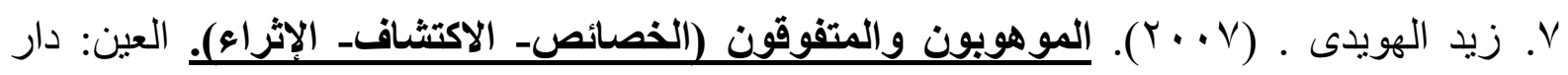

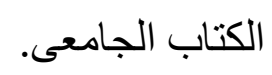

^. سليمان عبد الواحد يوسف. (1) (1). تربية المتميزين ورعايتهم فحى مدارسنا (إنقاذ أمه). القاهرة:

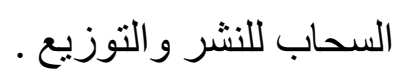

9. سناء نصر حجازى. (10 • (Y). تنمية الإبداع ورعاية الموهبة لدى الأطفال. طץ. الأردن: دار

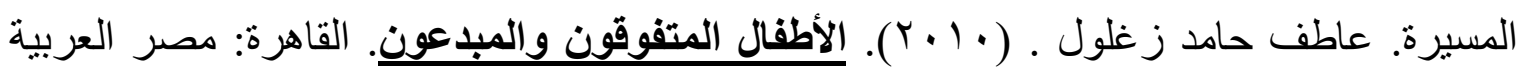

$$
\text { للنشر و التوزيع. }
$$

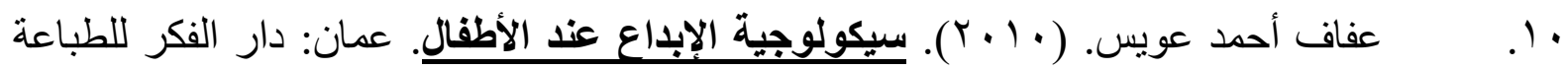

$$
\text { والنشر. }
$$

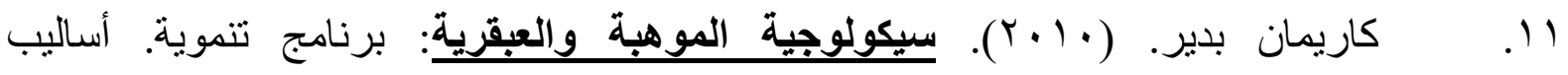

$$
\text { استكثافيةـ سبل دعم الموهوبين. القاهرة: عالم الكتاب. }
$$

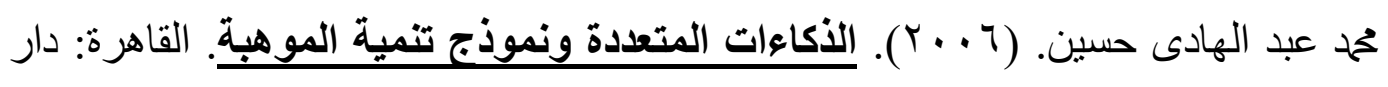

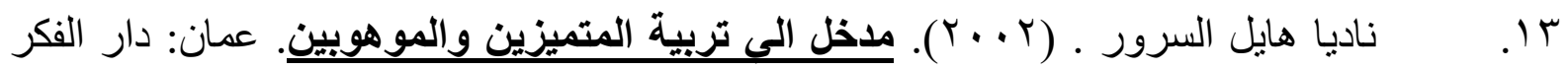


ناديا هايل السرور. (·(r). مدخل إلى تربية المتميزين والموهوبين. طه. عمان: دار $.1 \varepsilon$

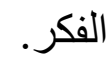

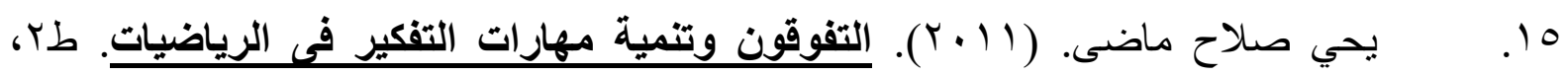
الأردن: دار ديبونو للنشر والتوزيع.

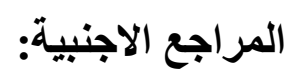

17-Miller (Angie L). (2012). Conceptualizations of creativity: comparing theories and models of giftedness. Routledge Taylor\& Francis Group ,34: 94- 103.

18-Renzulli (Joseph S). (2016). The three-ring conception of giftedness: $\mathbf{A}$ developmental modl for promoting creative productivity. article. University of Connecticut. (55-68).

19-The last word. (2010). An interview with Joseph S. Renzulli - on encouraging talent development. Melissa S. Mitchell.Journal of advanced academics. University of Connecticut. (157-166) 